\title{
Causal Contribution in War
}

DOI:

10.1111/japp.12341

\section{Document Version}

Accepted author manuscript

Link to publication record in Manchester Research Explorer

\section{Citation for published version (APA):}

Beebee, H., \& Kaiserman, A. (2020). Causal Contribution in War. The Journal of Applied Philosophy, 37(3), 364377. https://doi.org/10.1111/japp.12341

\section{Published in:}

The Journal of Applied Philosophy

\section{Citing this paper}

Please note that where the full-text provided on Manchester Research Explorer is the Author Accepted Manuscript or Proof version this may differ from the final Published version. If citing, it is advised that you check and use the publisher's definitive version.

\section{General rights}

Copyright and moral rights for the publications made accessible in the Research Explorer are retained by the authors and/or other copyright owners and it is a condition of accessing publications that users recognise and abide by the legal requirements associated with these rights.

\section{Takedown policy}

If you believe that this document breaches copyright please refer to the University of Manchester's Takedown Procedures [http://man.ac.uk/04Y6Bo] or contact uml.scholarlycommunications@manchester.ac.uk providing relevant details, so we can investigate your claim.

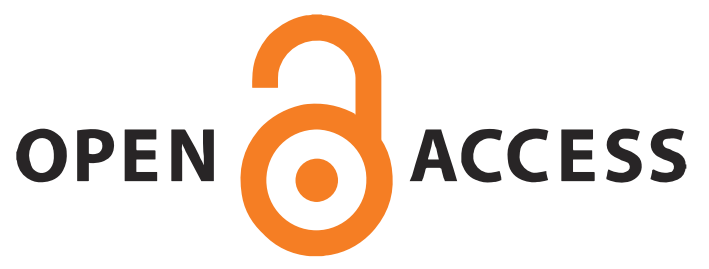




\title{
Pre-publication version: DO NOT CITE
}

\section{Causal Contribution in War}

\author{
Helen Beebee and Alex Kaiserman \\ Forthcoming, Journal of Applied Philosophy
}

\begin{abstract}
Revisionist approaches to the ethics of war seem to imply that civilians on the unjust side of a conflict can be legitimate targets of defensive attack. In response, some authors have argued that although civilians do often causally contribute to unjustified global threats - by voting for war, writing propaganda articles, or manufacturing munitions, for example their contributions are usually too small, or remote, to make them liable to be intentionally killed to avert the threat. What defenders of this view lack, however, is a theory of causal contribution. This paper sketches and defends a theory of causal contribution. We then apply it to the kinds of situation that defenders of the view are interested in. We argue, however, that since degrees of causal contribution turn out to be sensitive to particular features of the situation that are extrinsic to the agent's action, whether an agent makes a small or a large contribution to a threat may not only be very difficult to discern but in many cases may not line up very well with the kinds of intuition about liability that defenders of the view want to uphold.
\end{abstract}

\section{Introduction}

According to orthodox just war theory, combatants in armed conflicts do not have rights against being intentionally killed. But this position has come under sustained attack from moral theorists in recent years. What grounds permissible killing in war, they argue, is just what grounds permissible killing in ordinary life. The right to life is universal; if a combatant lacks such a right, it's not in virtue of being a combatant, but rather in virtue of having forfeited her right by wrongfully contributing to an unjustified lethal threat to another person, thereby rendering her liable to be killed in self- or other-defence.

One consequence of this approach is that not all combatants are equal. If the armed forces of country A unjustifiably threaten the citizens of country B, they may forfeit their rights not to be killed by the armed forces of B. But in threatening to respond in this way, the armed forces of B do not forfeit their rights against being intentionally killed, because the threat they pose is justified. In some ways, then, this revisionist approach to the ethics of war offers 
more moral protections to agents in armed conflicts than traditional just war theory. But the view also has consequences in the other direction: if combatants shouldn't be stripped of their rights to life simply in virtue of being combatants, then neither should non-combatants be allowed to keep their rights to life simply in virtue of being non-combatants. The civilians of A may have wrongfully contributed in all kinds of ways to the unjustified threat to B: by voting for the war, manufacturing arms, providing food and medical assistance, or writing pro-war articles, for example. The revisionist seems forced to concede that these civilians, as well as the combatants they support, are legitimate targets of defensive attack.

Some authors accept this conclusion. Helen Frowe, for example, argues that many civilians on the unjust side of a war will indeed have forfeited their rights not to be intentionally killed, and are morally immune from harm only to the extent that it is impossible to identify them or to attack them without causing significant collateral damage to innocent civilians. ${ }^{1}$ But others have suggested that although many non-combatants contribute to unjustified global threats, their contributions are usually too small, or remote, or insignificant, to make them liable to defensive attack. Jeff McMahan, for example, claims that "although the medic's act is a causal condition of the unjust combatant's continuing to pose an unjust threat, its causal contribution is too remote for it to be an act of war". ${ }^{2}$ Similarly, Seth Lazar claims that, "[i]n both regular and irregular warfare, very few noncombatants are sufficiently causally responsible for unjustified threats to be liable". ${ }^{3}$ And according to Cécile Fabre, one "cannot regard mere (wrongful) participation in a wrongful venture as a sufficient condition for liability to direct attack. Rather, a contribution must, on its own individual terms, meet a threshold of causal significance in order for its author to be liable". ${ }^{4}$ Note that this is not merely the view that the threats to which civilians causally contribute wouldn't be averted by killing them. Rather the claim seems to be that, even if killing a pro-war civilian would avert an unjustified threat (perhaps by scaring her leaders into ordering a retreat, for example), it would be morally impermissible to do so, in virtue of the 'insignificance' of her contribution to the threat. 5

Proponents of such a view have typically had a lot less to say about what they mean by 'causal significance', however. As such it's not especially clear whether the view actually has the consequences its proponents take it to have. Is the army medic's contribution to the threat posed by his patient more or less 'remote' than that of the mechanic in the factory that manufactured the soldier's ammunition? Does the propaganda writer make a larger or a smaller causal contribution to the threat her country poses than the army private too scared to fire her weapon? We simply lack the resources to answer these questions. This invites the legitimate accusation that just war theorists are simply using the idea of 'causal contribution' as a placeholder for whatever will deliver what they have pre-theoretically decided are the 
correct results - usually, the result that unjust civilians are not liable and unjust combatants are.

Our aim in this paper is therefore to develop a general metaphysics of causal contribution that can be applied to these debates in the ethics of war. Our aim is not to defend the view that degrees of causal contribution make a difference to liability; rather, we simply want to try and state the view with a greater level of precision than has been achieved thus far. Only then, we believe, will it be possible to determine whether the view allows us to draw the kinds of moral distinctions between combatants and civilians, or between different kinds of civilians, that some just war theorists have tried to defend.

Our discussion is structured as follows. We start in section 2 by sketching an account of causal contribution that one of us has defended elsewhere, ${ }^{6}$ before using it in section 3 to formulate a general principle we take to be implicit in the quotes above. Then, in section 4 , we examine the consequences of such a principle for liability in war, and in particular, whether such a principle could be used to justify any moral distinctions between different kinds of people on the unjust side of a war. Our conclusions will be mostly sceptical. In a sense to be explained, facts about degrees of causal contribution depend very sensitively on extrinsic details of the case. Driving munitions to the front line might make a large contribution to a threat in some circumstances and a small contribution in others; the same goes for providing medical care or tightening screws on a tank engine. Hence regardless of whether degrees of causal contribution do make a difference to liability - and, to repeat, we do not commit ourselves either way on this question - they do not allow us to draw any neat moral lines between different kinds of people, or even different kinds of activities, on the unjust side of a war.

\section{A Theory of Causal Contribution}

The theory of causal contribution we will be offering builds on a tradition - championed by J. L. Mackie ${ }^{7}$ and, more recently, Richard Wright ${ }^{8}$, among others - of thinking of causes as minimally jointly sufficient in the circumstances for their effects. On this view, a plurality of events $X_{1}, \ldots, X_{\mathrm{n}}$ collectively caused an effect $Y$ if and only if, (i) $X_{1}, \ldots, X_{\mathrm{n}}$ were jointly sufficient in the circumstances for $Y$, and (ii) no proper sub-plurality of $X_{1}, \ldots, X_{\mathrm{n}}$ were jointly sufficient in the circumstances for $Y$ (so that each of $X_{1}, \ldots$, and $X_{\mathrm{n}}$ were 'non-redundant' or, if you like, necessary to the sufficiency of $X_{1}, \ldots, X_{\mathrm{n}}$ for $Y$ ). To be a cause of $Y$ is then simply to be one of a plurality of events that collectively caused $Y .{ }^{9}$

Note that causation is a relation between pluralities of events and individual effects, on this view. We can illustrate this point by means of an analogy. Suppose we tell you that the book 
Good Omens was authored by Terry Pratchett and Neil Gaiman. By this we don't mean that Pratchett authored Good Omens and Gaiman also authored Good Omens; nor do we necessarily mean that Pratchett authored one part of Good Omens and Gaiman the other. Rather we simply mean that Pratchett and Gaiman authored Good Omens together. They are both authors of Good Omens in virtue of having contributed to the authoring of it. The same is true of causation, on the view described above. Suppose we tell you that a car crash was caused by the driver's drunkenness and a rainstorm. By this we don't mean that the drunkenness caused the crash and the rainstorm also caused the crash; ${ }^{10}$ nor do we mean that the drunkenness caused one part of the crash and the rainstorm the other. Rather we simply mean that the drunkenness and the rainstorm caused the crash together. They were both causes of the crash in virtue of having contributed to the causing of it.

Authoring is a non-scalar relation - it makes no sense at all to say that Pratchett authored Good Omens 'more' than Gaiman did. But this is perfectly consistent with different authors contributing to the authoring of a book to different extents - Pratchett may have had the majority of the ideas for Good Omens, for example, or done the majority of the research. The same, we think, is true of causation. Causing is a non-scalar relation - it makes no sense at all to say that the drunkenness caused the crash 'more' than the rainstorm did. But this is perfectly consistent with the possibility of different causes contributing to the causing of an effect to different extents.

What we now need is a way of measuring one event's degree of contribution to a causing of some effect. A natural way to do this is in probabilistic terms. ${ }^{11}$ We'll use the following familiar notation: ' $\mathrm{P}(p \mid q)$ ' denotes the objective probability of $p$ conditional on $q .{ }^{12}$ Very roughly speaking, one can think of the objective probability of a proposition as the 'fraction' of possible worlds in which that proposition is true. ${ }^{13} \mathrm{P}(p \mid q)$, then, is equal to the fraction of $q$-worlds that are also $p$-worlds. The objective probability of rolling a six with a fair dice is $1 / 6$; the objective probability of rolling a six conditional on rolling an even number is $1 / 3$; and so on.

Now let $d, r$, and $c$ be the propositions that the drunkenness, the rainstorm and the car crash, respectively, occur, and let $b$ be the conjunction of all relevant background conditions'. ${ }^{14}$ The drunkenness and the rainstorm were jointly, but not individually, sufficient in the circumstances for the crash; hence $\mathrm{P}(c \mid d \& r \& b)=1$, whereas $\mathrm{P}(c \mid d \& b)$ $<1$ and $\mathrm{P}(c \mid r \& b)<1$. But suppose also that $\mathrm{P}(c \mid d \& b)>\mathrm{P}(c \mid r \& b)$ - the probability of the crash occurring conditional on the drunkenness occurring is greater than the probability of the crash occurring conditional on the rainstorm occurring, in the circumstances (in possible worlds terms: the crash occurs in a greater fraction of the worlds in which the 
drunkenness occurs than the worlds in which the rainstorm occurs). This seems to us to be a case in which it would be appropriate to say that the drunkenness contributed more than the rainstorm to the causing of the crash (because, roughly speaking, it came closer to being sufficient for the crash by itself).

This suggests the following definition of the drunkenness's degree of contribution to the causing of the crash:

$$
\frac{\mathrm{P}(c \mid d \& b)}{\mathrm{P}(c \mid d \& b)+\mathrm{P}(c \mid r \& b)}
$$

The rainstorm's degree of contribution to the causing of the crash will then be:

$$
\frac{\mathrm{P}(c \mid r \& b)}{\mathrm{P}(c \mid d \& b)+\mathrm{P}(c \mid r \& b)}
$$

Notice that the two degrees of contribution sum to 1 - in effect, what we're doing is comparing how close each event came to being individually sufficient for the crash.

We can generalize this definition to causings involving more than two events in a natural way. Suppose a plurality of events $X_{1}, \ldots, X_{\mathrm{n}}$ collectively caused an event $Y$, and let $x_{1}, \ldots, x_{\mathrm{n}}$ and $y$ be the propositions that $X_{1}, \ldots, X_{\mathrm{n}}$ and $Y$, respectively, occurred. Then $X_{\mathrm{i}}$ 's degree of contribution to the causing of $Y$ by the plurality of events $X_{1}, \ldots, X_{\mathrm{n}}$ (relative to background conditions $b$ ) is given as follows:

$$
\frac{\mathrm{P}\left(y \mid x_{\mathrm{i}} \& b\right)}{\sum_{j=1}^{n} \mathrm{P}\left(y \mid x_{\mathrm{j}} \& b\right)}
$$

In words: an event's degree of contribution to a causing of some effect is equal to the probability of the effect occurring conditional on the cause occurring, divided by the sum of the conditional probabilities for all the other events involved in that causing.

To illustrate this account, let's apply it to the car crash case. Suppose first that the driver was really drunk. Although his drunkenness wasn't by itself sufficient for the crash, any number of potential distractions would have been enough for him to lose control of his vehicle - a butterfly on the wing-mirror, a funny-shaped cloud, etc. The rainstorm, meanwhile, wasn't particularly severe; it only contributed to the causing of the crash by somewhat impeding the driver's vision, since he was too drunk to operate the windscreen wipers. On these facts, $\mathrm{P}(c$ $\mid d \& b$ ) is close to 1: conditional on the driver being in his inebriated state, it was very likely, given the background circumstances, that the crash would have occurred one way or the 
other. On the other hand, since the rainstorm would have posed no danger to a sober driver, $\mathrm{P}(c \mid r \& b)$ is not much higher than $\mathrm{P}(d \& b)$, the unconditional probability in the circumstances of the driver being as drunk as he was. Suppose for the sake of argument that

$\mathrm{P}(c \mid d \& b)=0.9$ and $\mathrm{P}(c \mid r \& b)=0.2$; then it follows that the drunkenness contributed to degree 0.82 to the causing of the crash and the rainstorm to degree 0.18.

Alternatively, suppose that the rainstorm was incredibly severe, so that any number of slight lapses in concentration would have been enough for the driver to lose control of the vehicle. The drunkenness, meanwhile, was fairly modest; it only contributed to the causing of the crash by reducing the driver's reaction time by a few milliseconds. On these facts, $\mathrm{P}(\mathrm{c} \mid r \&$ $b$ ) is close to 1: conditional on the rainstorm occurring, it was very likely that the crash would have occurred one way or the other. On the other hand, since the drunkenness would have posed no danger to the driver in normal weather conditions, $\mathrm{P}(c \mid d \& b)$ is not much higher than $\mathrm{P}(r \& b)$, the unconditional probability in the circumstances of the rainstorm occurring. If the rainstorm was particularly unlikely in the circumstances - a freak occurrence, perhaps - then it follows that the driver's drunkenness contributed only a negligible amount to the causing of the crash.

\section{Causal Contribution and Liability}

The harm an agent is liable to suffer to avert a threat to someone else plausibly depends on several factors: ${ }^{15}$ the severity of the threat, the culpability of the agent's intentions, the nature of agent's evidence, and the availability and costs of alternative courses of action, to name a few. But most people believe that there is a causal condition on liability too - an agent is liable to be harmed to avoid a threat only if their actions contributed to bringing the threat about. ${ }^{16}$ Suppose for example that D negligently drops a lighted cigarette which starts a forest fire. The fire is extinguished; but sometime later a lightning strike starts another fire which threatens V's life. No matter how blameworthy D's actions might have been, he has not forfeited his right not to be used as a human shield to help V escape, because his dropping the cigarette wasn't a cause of the threat now facing V.

If causal contribution comes in degrees, however, the following view naturally suggests itself:

DEGREES: The harm an agent is liable to suffer to avert a threat to someone else depends, inter alia, on the degree of contribution her actions made to the causing of the threat.

Note that it doesn't necessarily follow from DEGREES that there is some fixed threshold of causal contribution to a threat below which an agent is not liable to be killed to avoid it - if the threat is sufficiently severe, or the agent's intentions sufficiently culpable, she may be 
liable to be killed even if her actions contributed only a small amount to the causing of the threat. ${ }^{17}$ Nevertheless, an agent's degree of contribution to the causing of a threat is one of the factors that goes into determining the harm she is liable to suffer to avert it, according to DEGREES. If two agents both culpably contribute to the causing of a serious threat that can only be averted by killing one of them, it follows from DEGREEs that the agent who has forfeited her right to life is the one who made the larger contribution, all other things being equal.

Before examining the consequences of DEGREES for the ethics of war, it will be useful to distinguish the notion of causal contribution we have in mind from some other, closely related concepts. Some authors talk of the 'causal contribution' of an event in terms of the "the part or proportion of an outcome that [the event] causes". ${ }^{18}$ Suppose A unjustifiably threatens to kill one innocent person and B unjustifiably threatens to kill two innocent people. Suppose also that killing one of A or B will scare the other into surrendering, so that the total threat to all three innocent lives can be averted by killing one of the aggressors. It seems clear that, all other things being equal, it is B who should be killed, because her actions caused a larger part of the total threat.

The problem with this approach is that threats in war typically can't be 'decomposed' into parts in this way. Suppose for example that the cabinet members of country A all vote to commence unjustified hostilities against country B. Killing just one of the cabinet members will scare the others into agreeing to a retreat. Each vote was a cause of the threat now facing A; but this time, the threat can't be divided into 'parts', such that each vote caused one part each. The account of causal contribution sketched above can handle these more complicated cases, however. Suppose for example that one of the cabinet members is particularly influential, so that the others are more likely to vote in favour of a motion if she does the same - then it would follow that this cabinet member contributed more to the causing(s) of the threat than did the others. ${ }^{19}$ DEGREES would then require us to target the influential cabinet member over the others, all other things being equal, even though there is no 'part' of the threat that this cabinet member individually caused.

Other authors talk of 'causal contribution' in terms of the difference a cause made with respect to an effect. According to Elliot Sober, for example, "the contribution a cause makes and the difference it makes seem to be one and the same issue". ${ }^{20}$ Suppose that A and B both contributed to the causing of an unjustified threat to $\mathrm{V}$, which can only be avoided by killing one of them. But for A's action, $\mathrm{V}$ would still have faced an unjustified threat, albeit a less severe one; whereas but for B's action, V wouldn't have faced a threat at all. Some might 
argue that, all other things being equal, it is B who should be killed, because her action made more of a difference vis-à-vis the threat.

But again, many cases in war are not a simple as this. In the cabinet case, for example, no individual vote made any difference at all to the threat, because had any one of them voted against the motion, it would still have passed with a majority. Indeed it's plausible to suppose that cases like these are the norm in the context of global threats that characterise modern conflicts - almost all such threats are massively overdetermined, so that the difference made by any one individual is zero (a munitions factory might employ 100 people, but will operate just as effectively with only 99 workers, for example). Our account of causal contribution can handle cases of overdetermination, however. ${ }^{21}$ Even if a threat was caused multiple times, by multiple different pluralities of events, one can still calculate an event's degree of contribution to each of the causings of the threat to which it contributes.

Michael Moore has argued that there is "a diminishment in the strength of causation in proportion to the number of events through which it is transmitted". ${ }^{22}$ According to Moore, then, $X$ 's 'causal strength' with respect to $Y$ is proportional to the number of events in the 'causal chain' between $X$ and $Y$. Suppose again that A and B both contribute to the causing of an unjustified threat which can only be averted by killing one of them. Suppose also that B's act was more 'proximate' to (and A's act more 'remote' from) the threat, in the sense that the causal chain connecting A's act to the threat is 'longer' than that connecting B's act to the threat, with more intervening events. Then on Moore's view it seems to follow that it is B who should be killed.

As one of us has argued elsewhere, however, ${ }^{23}$ it's not clear whether talk of the 'length' of a causal chain is really coherent. If $X$ is a cause of $Y$, which in turn is a cause of $Z$, then on Moore's view $X$ has less causal 'strength' with respect to $Z$ than does $Y$, since there is at least one additional element in the causal chain between $X$ and $Z$ compared to the chain between $Y$ and $Z-v i z, Y$ itself. But particular causal chains can be considered at different levels of granularity - from a more fine-grained perspective, there may be many more events in the causal chain between $X$ and $Z$ than just $Y$. What we really need, therefore, is a way of counting the number of events in a causal chain that can be consistently applied across different cases - and Moore doesn't provide such a measure.

More importantly, even if such a measure could be provided, there is no guarantee at all that it would deliver the right results. Consider the following two cases, for example:

Remote 
D plants a bomb under V's house and lights the fuse. Unbeknownst to D, the fuse is made out of incredibly slow-burning material. Days later, the bomb eventually explodes, killing V.

\section{Proximate}

D plants a bomb under V's house and lights the fuse. Unbeknownst to D, most of the fuse is made of flame-resistant material and it quickly fizzles out. Seconds later, however, the bomb is struck by lightning and explodes, killing V.

It's true in both these cases V's death wouldn't have occurred but for D's wrongful action. Yet intuitively, D's action made a smaller contribution to the death in Proximate than it did in Remote. ${ }^{24}$ It's not clear how Moore's account can actually deliver this result, however. Although there are, from a sufficiently fine-grained perspective, lots of intervening events in the causal chain between D's action and V's death in Proximate - the fuse being extinguished, the bomb being hit by lightning, and so on - there are also lots of intervening events in Remote - the first third of the fuse burning, the second third of the fuse burning, and so on. So if we fix on a particular measure of events in a causal chain in such a way as to deliver the result that D's action made a small contribution to the causing of V's death in Proximate, it's not at all obvious that our chosen measure wouldn't likewise imply that D's action made a small contribution to the causing of V's death in Remote too, for exactly the same reason.

In a later paper, Moore claims that the idea of counting the number of intermediate events should only be seen as a proxy for a measure of causal contribution. Since an event typically has multiple causes, he argues, the degree of causal contribution to an effect $E$ will generally (but not invariably) diminish the further back in the causal chain leading to $E$ we go, since at each intermediate stage various events will have to come together to collectively cause $E$. Thus, for example, "if dryness were $20 \%$ of the cause of the match lighting, which itself was $40 \%$ of the cause of the match at t1 being dropped, which was $40 \%$ of the cause of the match entering the beaker, which was $50 \%$ of the cause of the explosion, then the dryness of the match was only $1.6 \%$ of the cause of the explosion". ${ }^{25}$ This may be correct, but of course what is now needed - and, as he readily admits, Moore does not provide - is an account of causal contribution. This is just what we tried to provide in the previous section. Moreover, when applied to the cases above, our measure seems to get the right results - D's action made a large contribution in Remote and a small contribution in Proximate, because (inter alia) conditional on D lighting the fuse in Remote, it is very likely (in the circumstances) that $\mathrm{V}$ will eventually die, whereas conditional on D lighting the fuse in Proximate, it's not at all likely, given that the fuse is made of flame-resistant material, that $\mathrm{V}$ will die (it was a massive co-incidence that the lightning struck in precisely the location where the bomb had been 
planted). Neither the interval of time nor the number of intermediate events (even supposing there is a sensible way of counting them) between an agent's action and a threat need have anything to do with the action's degree of contribution to the causing of the threat, on the view defended here.

Victor Tadros has recently argued that no notion of 'degrees of causal contribution' makes any difference to liability. ${ }^{26} \mathrm{He}$ accepts, we take it, that whether one's actions causally contributed to a threat is one of the factors that go into determining the harms one is liable to suffer to avert it; he just denies that there is any sense in which one is liable to suffer more harm in virtue of contributing to a greater extent to the causing of the threat. Since our aim here is not to defend the view that degrees of causal contribution matter to liability, we won't attempt to respond to his arguments directly. But it is worth noting one concern we have about Tadros's methodology. His strategy is to consider cases involving two agents who differ in their 'degree of contribution' to a threat, in some proposed sense of that term, before soliciting intuitions about whether there are "stronger reasons" to kill one over the other. But it's not at all clear to what extent our intuitions about who we have most reason to kill are really tracking the facts about who is liable to be killed in these kinds of cases. Anyone who thinks that causation is a necessary condition on liability is already committed to a certain amount of moral luck - if A and B both intentionally start forest fires, but A's fire, by some happy accident, is extinguished before it can do much harm, then while $\mathrm{B}$ may be liable to be used as a human shield to save potential victims of his fire, A is not, even though there's a sense in which A and B are both equally blameworthy for their actions, since it was only a matter of luck that A's fire was extinguished and B's was not. Insofar as facts about blameworthiness come apart from facts about liability, then, we need to make sure that when we solicit intuitions about who we have 'stronger reason' to kill in cases like the ones Tadros considers, our intuitions are tracking the latter and not the former.

In her contribution to this volume, Sartorio defends an even more radical position, namely that the very concept of 'degrees of causal contribution' is incoherent - causation, in other words, does not come in degrees. ${ }^{27}$ Her argument for this, roughly speaking, proceeds as follows: there are at least two different ways of thinking about 'degrees of causal contribution', depending on whether we take as our starting point the idea that causes are necessary for their effects or the idea that they're sufficient; but since there are cases in which these notions come apart, it's not always clear which event made the larger contribution; so the whole idea of 'degrees of causation' must have been an illusion from the start. Of course, one way to respond to this argument would be to simply reject its presupposition that there is just one notion of 'degrees of causal contribution', as opposed to several divergent, but perfectly coherent, notions. But we suspect Sartorio's real complaint 
here is that the two notions of 'degrees of causal contribution' she identifies both seem to be relevant to evaluations of moral responsibility, so that it's not always clear who is more responsible in cases in which these notions come apart. At least one of us is sceptical about the stability of the intuitions here ${ }^{28}$ but even if Sartorio is right that there is more than one morally relevant notion of degrees of causation, that wouldn't imply that talk of 'degrees of causation' is incoherent. Rather, we would simply have to concede that there is more than one causal dimension to moral responsibility, and hence potentially no answer to the question of who is more morally responsible in cases in which two people differ in opposing directions along these two different dimensions. Although the decision-theoretic issues arising from moral incomparability are now well-known, ${ }^{29}$ this particular manifestation of the problem - particularly for decision-making in war - remains underexplored.

\section{Causal Contribution in War}

As we said at the outset, one recent element of the just war debate has been the discussion of whether - and if so, how - a causal distinction between combatants and civilians on the unjust side can be drawn, which would at least partially explain why combatants on the unjust side have forfeited their rights not to be killed while all (or perhaps just some) civilians have not. What has been lacking from that debate so far is a viable theory of causal contribution, against which the relative contributions of various kinds of participants in the war effort - politicians, strategists, effective and ineffective combatants, medics, arms suppliers, the publishers of propaganda, voters, workers in munitions factories, and so on might in principle be judged; and that is what we have aimed to provide.

Seth Lazar poses what he calls the 'responsibility dilemma' for liability-based approaches to the ethics of war. ${ }^{30}$ Suppose an agent is liable to be killed only insofar as her degree of moral responsibility for an unjust threat exceeds some threshold, along the culpability, epistemic and (perhaps) causal dimensions. Lazar argues that if we set this threshold high enough to ensure that most civilians on the unjust side of a war are not liable to be killed, it will turn out that most combatants of the unjust side won't be liable to be killed either; and if we set the threshold low enough to ensure that most combatants on the unjust side are liable to be killed, then it will turn out that most civilians on the unjust side are liable to be killed as well. ${ }^{31}$ As Saba Bazargan puts it, "the liability based account seems to force us to choose between a version of pacifism, and total war".30

Cécile Fabre suggests that a similar dilemma would arise even for attempts to draw distinctions between different kinds of civilians. The target of Fabre's paper is the so-called 'functionalist view', according to which military contributions to the war effort are morally 
different in kind from welfare contributions, in a way that explains why civilians who, for example, work in munitions factories are liable to defensive attack whereas those who, say, provide medical treatment to injured combatants are not. Fabre rejects this view, on the grounds that "whether a civilian is liable to attack depends on the extent to which he is causally and morally responsible" 33 for an unjustified threat, regardless of "whether their contributions to unjust lethal threats are military or welfarist". 34 In other words, "a contribution must, on its own individual terms, meet a threshold of causal significance in order for its author to be liable"; 35 and there is no reason in general, Fabre argues, to think that so-called 'military' contributions to unjustified threats are any more likely to meet this threshold than so-called 'welfare' contributions.

We agree with Fabre that DEGREES cannot be used to justify any neat moral lines either between combatants and civilians or between civilians who make military contributions and those who make welfare contributions. But Fabre's argument for this (as she readily admits) is not based on any independent theory of causal contribution. Instead she proceeds by giving some examples of what she takes to be small and large causal contributions:

Tightening screws on tank engines, testing the sweat-absorbing capacities of the clothes which soldiers will wear in the desert, and adjusting the speed level of food-packaging machines do not, it seems to me, pass the threshold. Nor, for that matter, does designing a tiny piece of equipment which goes into a gun do so. By contrast, taking overall responsibility for negotiating and drafting sales contracts between one's factory and the army might; so might driving a truckload of munitions or protective clothing to an armory division, and so on. ${ }^{36}$

According to Fabre, then, an agent who merely tightens the screws on a tank engine makes a negligible contribution to the causing of the threat the tank goes on to pose, whereas an agent who drives a truckload of munitions to the front line makes a much larger contribution to the causing of the threat those munitions go on to pose. She provides no argument for these claims; in the absence of an account of causal contribution, we are asked to agree that the claims are intuitively true. Yet it's not at all clear that these claims are true in general, on the account of causal contribution defended here. To see this, start by assuming that screwtightening is a mundane task performable by any of many available people, and the tightness of the screw is checked many times before the tank is sent to the front line. The tank then poses an unjustified threat to someone. Conditional on all the other causes of the threat occurring, it's very likely that the threat would have occurred, because it's very likely that someone would have tightened the screw (and even if they hadn't, the tank probably would have remained operational anyway). In this case, then, the screw-tightening's degree of contribution to the causing of the threat will indeed be very small. But now suppose that the tightening of the screw could only have been done by a very specialized technician, and was 
vital to the lethal capacity of the tank. Suppose also that the screws had been checked several times already, and it was only by chance that the technician noticed that this particular screw was loose. Conditional only on the other causes of the threat occurring, it's now very unlikely that threat would have occurred, because the technician could very easily have failed to notice that the screw was loose, and if he hadn't noticed, the tank wouldn't have posed a threat at all. In this case, then, the screw-tightening's degree of contribution to the causing of the threat might well be very large. By the same token, if the task of driving the munitions truck is one that any number of drivers can perform, and the collective consequences for the drivers of failing to drive it to its destination are severe (so that there are plenty of potential back-up causes waiting in the wings, each of which is very likely to occur if none of the others do), then the particular person who happens to perform the task will probably make only a small contribution to the causing of the threat. But if there is only one driver who went out of his way, against the odds, to drive the munitions to a group of people prepared to commence hostilities immediately, then the driver may well make a large contribution.

Thus although we agree with Fabre that DEGREES cannot be used to draw any moral lines between military contributions and welfare ones, we also think, apparently contra Fabre, that DEGREES can't even be used to draw any moral lines between, say, civilians who tighten screws on a tank engine and those who drive munitions to the front line. The degree of contribution these actions make to a causing of a threat depend very sensitively, not just on the intrinsic properties of the actions themselves, but also on those of the other causes, the presence or absence of potential back-up causes, and other factors besides.

Indeed, the details of the case matter to such an extent that one may justifiably wonder how on earth one could sensibly go about calculating particular degrees of causal contribution in actual cases, especially given how much uncertainty there already is in conflict situations. How can we insist that soldiers only kill those who are liable to be killed, when figuring out who is liable is so hard? We sympathise with this worry. But our aim in this paper was to provide the required theoretical underpinning for claims about degrees of causal contribution, and not to provide an instruction manual for the application of the theory to real-life cases. It may well be that our epistemic position with respect to the relevant facts is so impoverished in situations of war that drawing crude lines between different groups of people is the best we can do. But we take no stand on these kinds of practical questions.

\section{Conclusion}

The defender of DEGREES cannot rest content with intuitive appeals to what kinds of activity make small or large contributions to causings of unjustified threats in conflict situations. We have presented a theory of causal contribution that might be used to fill this lacuna in 
DEGREES and shown how it applies to the debate about the liability of individuals to be killed. We have argued that, given this account of causal contribution, Fabre is right that there is no clear line to be drawn - at least on the grounds of causal contribution alone - between combatants and civilians, or indeed between doctors and munitions factory workers. On the other hand, the account we have sketched does not force us to choose between 'a version of pacifism and total war': since there may be significant differences in the degrees of causal contribution that individuals make, it's plausible to suppose that there will be some way of setting the thresholds on liability in such a way that non-trivial numbers of people end up on either side of it. The point is just that such a distinction probably won't line up very well with the kinds distinction that have historically been considered morally important, such as the distinction between civilians and combatants, or between military contributions and welfare contributions.

We have also argued, however, that there is no clear line to be drawn even between, say, screw-tighteners and the drivers of munitions trucks, since an action's degree of contribution to a causing of a threat does not supervene on the intrinsic properties of that action. It might be true that in general those who play a particular kind of role - mending tanks, working in munitions factories, developing appropriate clothing, or whatever - are likely to meet or fail to meet the required threshold; but from a metaphysical point of view such rough-and-ready generalisations can only serve as a best guess, in a situation of extreme and inevitable epistemic uncertainty, as to who has or has not in fact forfeited their right to life.

We suspect that any viable account of causal contribution will have this result. After all, in the messy world of human affairs causal generalisations are normally only rough and ready. We might reasonably assume that the actions of a particular munitions factory worker were amongst the causes of the bomb's going off; after all, the factory produced the bomb and she is one of the assembly-line workers. But we may of course be wrong; she may have been off work that day, or sent out on an errand, or whatever. Similarly, we might reasonably assume that - if she did contribute - her contribution was large or small, given our incomplete knowledge of the factory. But again we may be wrong: the precise details of how the bomb was produced and the circumstances in which it was produced may have involved all manner of features that in fact made her contribution less (or greater) than we assumed. No theory of causal contribution can guarantee otherwise. Whether this feature of causal contribution serves to undermine the prospects for DEGREES - or indeed any view that takes an individual's actual causal role in an unjustified threat to be a necessary condition on their liability to be killed - is a question we shall leave for others to judge.

Helen Beebee, University of Manchester, M13 9PL, UK, helen.beebee@manchester.ac.uk. 
Alex Kaiserman, Balliol College, University of Oxford, OX1 3BJ, UK, alexander.kaiserman@philosophy.ox.ac.uk.

\section{Acknowledgements}

Thanks to Victor Tadros, Carolina Sartorio, Helen Frowe, Massimo Renzo, Cécile Fabre, Jeff McMahan, and everyone at the 'Conversations on War' workshop in Valencia for their valuable comments on previous versions of this paper.

\section{Notes}

${ }^{1}$ Helen Frowe, Defensive Killing (Oxford: Oxford University Press, 2014).

${ }^{2}$ Jeff McMahan, 'The Ethics of Killing in War', Ethics, 114, 4 (2004): 693-733, p.711.

3 Seth Lazar, Sparing Civilians (Oxford: Oxford University Press, 2015), p.94.

4 Cécile Fabre, 'Guns, Food, and Liability to Attack in War', Ethics, 120, 1 (2009): 36-63, p.61.

5 These two claims are often run together: McMahan, for example, argues that "even morally responsible noncombatants normally only make a very slight causal contribution to their country's unjust war, so that attacking them would do little to diminish the threat their country poses or to advance the just cause"; McMahan op. cit., p.728. But at least as we will conceive of it, the question of how much an agent contributed to bringing about a threat is not the same as the question of how much difference killing her would make to the threat. See section 3, below.

${ }^{6}$ Alex Kaiserman, 'Causal Contribution', Proceedings of the Aristotelian Society, 116, 3 (2016): 387-394.

7 J. L. Mackie, 'Causes and Conditions', American Philosophical Quarterly, 2, 4 (1965): 245264 .

8 Richard W. Wright, 'Causation in Tort Law', California Law Review, 73, 6 (1985): 17351828; Richard W. Wright, 'The NESS Account of Natural Causation: A Response to Criticisms' in Markus Stepanians and Benedikt Kahmen (eds.) Critical Essays on "Causation and Responsibility” (Berlin: Walter de Gruyter, 2013), pp. 13-66.

9 The main rivals to sufficiency-based accounts of causation are counterfactual accounts of causation (e.g. David Lewis, 'Causation', The Journal of Philosophy, 70, 17 (1973): 556-567), which try to analyse claims like ' $X$ caused $Y$ ' in terms of what would have happened if $X$ hadn't occurred. In a nutshell, the main challenge to counterfactual accounts is capturing our intuitions in pre-emption and overdetermination cases, whereas the main challenge for 
sufficiency accounts is specifying a notion of sufficiency that doesn't make, say, effects of a common cause sufficient for each other. It is beyond the scope of this paper to adjudicate between these two approaches, of course; but for a comparative assessment of different measures of 'causal contribution' suggested by these different analyses of causation, see Alex Kaiserman, “More of a Cause': Recent Work on Degrees of Causation and Responsibility', Philosophy Compass, 13, 7 (2018): e12498.

${ }^{10}$ Unless, that is, the crash was overdetermined (that is, caused twice over). While it's plausibly impossible for two people to both individually author the very same book, most metaphysicians believe that it is possible for two events to each individually cause the very same effect (although see Peter Unger, 'The Uniqueness in Causation', American Philosophical Quarterly, 14, 3 (1977): 177-188).

${ }^{11}$ See Kaiserman, 'Causal Contribution', op. cit.

${ }^{12}$ We assume here that there are non-trivial objective probabilities, even in a deterministic world, which are distinct from the credences or degrees of belief it is rational for any actual agent to have.

${ }_{13}$ Talk of 'fractions' of possible worlds is clearly somewhat delicate given that there is an uncountable infinity of them - we'll pass over these difficulties here.

14 These will presumably include facts about the car, facts about the road surface, the fact that the universe didn't explode just before impact, and so on. How the background conditions are to be determined is a difficult question, which we won't address here (although see Alex Kaiserman, 'Necessary Connections in Context', Erkenntnis, 82, 1 (2017): 45-64). For our purposes, we require only the basic idea that there is a difference between the causes and the background conditions - between those events which caused an effect and those facts "without which the cause would not be able to act as a cause", as Plato once put it (Phaedo, 99a-b).

${ }^{15}$ Talk of 'averting' the threat should not - here and throughout - be understood as a matter of preventing the event or events that constitute the threat, but rather as a matter of preventing the harm that the threat is a threat of. If the citizens of country A vote for war, for example, the outcome of the vote itself can no longer be prevented; what can be prevented is the unjustified harm that will, without intervention, be caused to the citizens of country B by the war.

${ }^{16}$ For a dissenting view see Victor Tadros, 'Causation, Culpability and Liability' in C. Coons and M. Weber (eds.), The Ethics of Self-Defense (Oxford: Oxford University Press, 2016), pp. 110-130. 
${ }^{17}$ See Victor Tadros, 'Causal Contributions and Liability', Ethics, 128, 2 (2018): 402-431 and Lazar op. cit., p.49, on this point.

${ }^{18}$ Sara Bernstein, 'Causal Proportions and Moral Responsibility' in D. Shoemaker (ed.), Oxford Studies in Agency and Responsibility: Volume 4 (Oxford: Oxford University Press, 2018), p.168.

${ }^{19}$ See Kaiserman, 'Causal Contribution', op. cit.

${ }^{20}$ Elliott Sober, 'Apportioning Causal Responsibility', The Journal of Philosophy, 85, 6 (1988): 303-318. Northcott similarly defends a defends a measure of 'relative causal strength' where "the strength of a cause is how much difference it makes"; Robert Northcott 'Degree of Explanation', Synthese, 190, 15 (2013): 3087-3105, p.3090.

${ }^{21}$ See Kaiserman, 'Causal Contribution', op. cit.

${ }^{22}$ Michael S. Moore, Causation and Responsibility: An Essay in Law, Morals, and Metaphysics (Oxford: Oxford University Press, 2009), pp. 122-123.

${ }^{23}$ Helen Beebee, 'Legal Responsibility and Scalar Causation', Jurisprudence, 4, 1 (2013): 102-108.

${ }^{24}$ Moore seems to agree with this; see for example Moore op. cit. p.122.

25 Michael S. Moore, 'Author's Reply', Jurisprudence 4, 1 (2013): 121-137.

${ }^{26}$ Tadros, 'Causal Contributions and Liability', op. cit.

${ }^{27}$ Carolina Sartorio, 'More of a Cause?', Journal of Applied Philosophy (forthcoming). ${ }^{28}$ See Kaiserman, "More of a Cause", op. cit., ff.24.

${ }^{29}$ Nien-hê Hsieh, 'Incommensurable Values', in Edward N. Zalta (ed.), The Stanford Encyclopedia of Philosophy (Spring 2016 Edition), URL = <https://plato.stanford.edu/archives/spr2016/entries/value-incommensurable/>. ${ }^{30}$ Seth Lazar, 'The Responsibility Dilemma for Killing in War: A Review Essay', Philosophy and Public Affairs, 38, 2 (2010): 180-213.

${ }^{31}$ Lazar is primarily concerned with epistemic conditions on responsibility, but the point applies mutatis mutandis to causal conditions too.

${ }^{32}$ Saba Bazargan, 'Complicitous Liability in War', Philosophical Studies, 165, 1 (2013): 177195, p. 177.

33 Fabre op. cit., p.37.

34 Fabre op. cit., p.63. 
35 Fabre op. cit., p.61.

${ }^{36}$ Fabre op. cit., pp.76-7. 